\title{
Understanding the implant performance of magnetically controlled growing spine rods: a review article
}

\author{
Martina Tognini ${ }^{1}\left[\right.$ [ Harry Hothi ${ }^{1} \cdot$ Elisabetta Dal Gal ${ }^{1}$. Masood Shafafy ${ }^{2} \cdot$ Colin Nnadi $^{3} \cdot$ Stewart Tucker $^{4}$. \\ Johann Henckel ${ }^{1}$. Alister Hart ${ }^{1}$
}

Received: 2 September 2020 / Revised: 14 January 2021 / Accepted: 13 February 2021 / Published online: 5 March 2021

(c) The Author(s) 2021

\begin{abstract}
Purpose Early-Onset Scoliosis (EOS) (defined as a curvature of the spine $\geq 10^{\circ}$ with onset before 10 years of age) if not properly treated, can lead to increased morbidity and mortality. Traditionally Growing Rods (TGRs), implants fixated to the spine and extended every 6-8 months by surgery, are considered the gold standard, but Magnetically Controlled Growing Rods (MCGRs) avoid multiple surgeries. While the potential benefit of outpatient distraction procedure with MCGR is huge, concerns still remain about its risks, up to the release of a Medical Device Alert (MDA) by the Medicines and Healthcare Regulatory Agency (MHRA) advising not to implant MCGRs until further notice. The aim of this literature review is to (1) give an overview on the use of MCGRs and (2) identify what is currently understood about the surgical, implant and patient factors associated with the use of MCGRs.

Methods Systematic literature review.

Results Surgical factors such as use of single rod configuration or incorrect rod contouring might affect early failure of MCGRs. Patient's older age and higher BMI are correlated with rod slippage. Wear debris and distraction mechanism failure may result from implant design and iteration.

Conclusion Despite the complications reported, this technology still offers one of the best solutions to spine surgeons dealing with severe EOS. Lowering the complication rate by identifying risk factors for failure is possible and further studies in this direction are required. Once the risk factors are well described, some of these can be addressed enabling a safer use of MCGRs.
\end{abstract}

Keywords MCGR $\cdot$ MAGEC rods $\cdot$ EOS $\cdot$ Risk factors

\section{Introduction}

Magnetically Controlled Growing Rods (MCGRs) are distraction-based devices intended to surgically treat patients who suffer from Early-Onset Scoliosis (EOS). The aim of

Martina Tognini

martina.tognini.19@ucl.ac.uk

1 The Royal National Orthopaedic Hospital and Institute of Orthopaedics and Musculoskeletal Science, University College London, Stanmore, UK

2 Department of Trauma and Orthopaedics, Nottingham University Hospitals NHS Trust, Nottingham, UK

3 Nuffield Orthopaedic Centre, Oxford University Hospital, Headington, Oxford, UK

4 Great Ormond Street Hospital for Children, NHS Foundation Trust, London, UK
MCGRs is to control curve progression while allowing for spinal growth until its full development potential has been reached and conversion to final fusion is considered. The MAGEC (MAGnetic Expansion Control; NuVasive, SanDiego, USA) system is currently the only available magnetically controlled growing rod system, first licensed in Europe in 2009 and then approved by the FDA in 2017 [1]. Until then, Traditional Growing Rods (TGRs) were the gold standard for the treatment of severe EOS. MCGRs don't need the repeated rod distraction surgeries performed when a TGR is implanted, whose risks and socio-economic burden has been extensively debated in literature [2-6]. Recently, the benefits compared to the risks associated with the use of MCGRs have been questioned, leading to the Field Safety Notice (FSN) published on April 1st, 2020 by the manufacturer suspending the supply of MAGEC rods in the UK and Republic of Ireland. This FSN was immediately followed by a Medical 
Device Alert (MDA) by the Medicines and Healthcare Regulatory Agency (MHRA) in the United Kingdom advising not to implant MAGEC rods until further notice [7]. Prior to this, NuVasive had suspended the supply of the latest implant iteration, the MAGEC X [8].

Due to the complexity and heterogeneity of patients with EOS, the difficulties in successfully treating these patients are widely acknowledged. Many surgeons consider MCGRs as one of the best surgical treatment options available to them due to their less invasive approach. Nevertheless, the reported complication profile requires further study in order to better understand the underlying mechanisms of failure in these devices. The aim of this literature review is to (1) give an overview on the use of MCGRs and (2) identify what is currently understood about the surgical, implant and patient factors associated with the use of MCGRs.

\section{EOS}

EOS is defined as a curvature of the spine $\geq 10^{\circ}$ in the frontal plane with onset before 10 years of age [9]. The main risk associated with EOS in young children is impaired pulmonary function, due to the high risk of progressive spinal deformity and thoracic constraints at an early age, when lungs are still developing [10].

Normal spine growth (T1-S1 vertebral segment growth) is faster during the first 5 years, $2 \mathrm{~cm} /$ year on average, whereas between 5 and 10 years of age the total spinal growth is around $5 \mathrm{~cm}$ in total, on average [11]. From 10 years of age to adulthood, normal growth consists of $10 \mathrm{~cm}$, including adolescent growth spurt $(2 \mathrm{~cm} /$ year $)$. The majority of spinal curves are due to Adolescent Idiopathic Scoliosis (AIS), classified according to the curve pattern only (Lenke classification [12]). The prevalence of aetiologies in EOS is not known, but when compared to AIS idiopathic infantile scoliosis accounts only for $<1 \%$ of all cases while juvenile idiopathic scoliosis accounts for $12-21 \%$ of all cases of idiopathic scoliosis [13]. Other aetiologies include neuromuscular, congenital and syndromic EOS, which are often associated with comorbidities making the management of EOS more challenging. For this reason the most accredited classification system for EOS takes into account 4 main aspects of the deformity: aetiology, major curve magnitude, kyphosis and the annual rate of progression [14].

Treatment strategies and duration differ significantly based on both aetiology and the amount of anticipated growth remaining, which is higher in younger patients ( $<5$ years old). Patients with EOS are likely to develop Thoracic Insufficiency Syndrome (TIS), defined as the inability of the thorax to support normal respiratory function and lung development in growing children [10]. A Swedish study found twice the mortality rate in patients with untreated EOS by age 40 compared with that of general population [15]. In particular, the earlier the age of onset and the greater the major curve, the higher the mortality risk. The increased mortality in this study was almost exclusively due to respiratory failure.

\section{Treatment strategies for EOS}

\section{Non-operative treatment}

The two major non-operative treatments (Table 1) for spinal deformity are casting and bracing [6]. Casting for up to 64 months has proved to be able to prevent or delay surgical intervention [16]. Hence casting may be considered as an alternative to operative treatment or as a first step before growing rod surgery in patients with EOS, but it is not able to achieve the same amount curve correction reached by growing rod surgery [17]. If despite casting and/or bracing the curve progresses, surgery may be required.

\section{Guided growth and compression-based systems}

Growth modulation techniques are based on the idea of harnessing the growth potential of the patient's vertebrae while directing the spinal growth into a normal alignment. Guided growth systems consist of rods attached (not rigidly) to anchors placed at multiple vertebrae. Examples of guided growth systems are Shilla growth guidance system (SGSS) and modern Luque trolley (MLT). SGGS is a new technique based on the use of pedicle screw fixation and dual rods, able to slide in order to follow the spine growth $[18,19]$. Few studies are available on this technique, showing similar complication rates when compared to TGR [20,21]. In addition to normal implant-related failure, when growth potential is particularly high rods slippage from the screws is frequent, leading to revision surgery [19]. Similar to SGGS, MLT is not FDA approved and the effect of wear debris needs further considerations. Compression-based systems like Vertebral Body Stapling (VBS) and Vertebral Body Tethering (VBT) on the other hand are based on the idea of inhibiting spinal growth on the convex side of the curve while preserving the motion of the whole spine without fusion [22, 23]. Strict indications, limited applications and anterior surgery causing bowel and pulmonary complications are the main drawbacks of these two techniques, which are not yet in routinely used for EOS patients yet.

\section{Distraction-based techniques}

The most common surgical treatment for EOS is based on the use of distraction rods [9]. These devices are aimed at allowing spinal growth while correcting the major curve, applying traction between proximal and distal anchors joined 


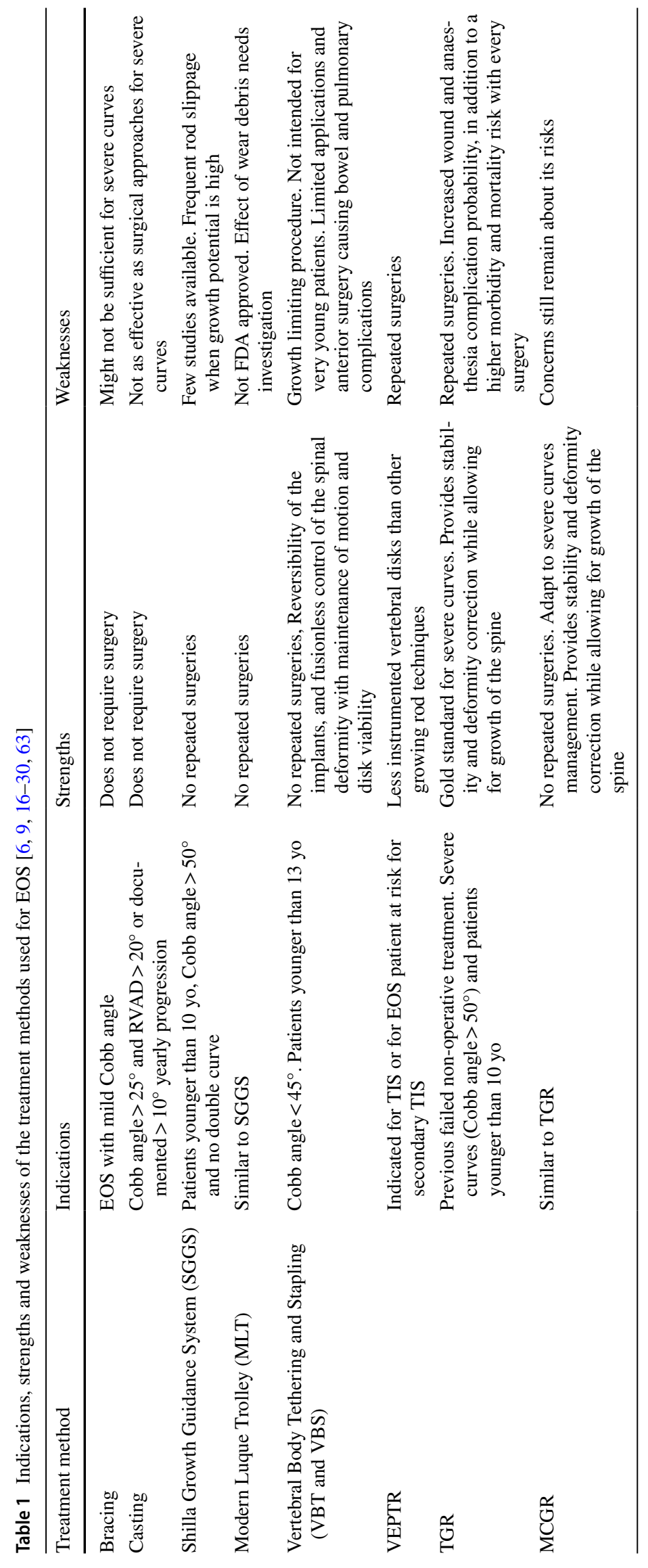


by expandable rods. As the child grows, rods must be lengthened, approximately every 6 months, depending on the type of device. There are three main types of growing rods: Vertical Expansion Prosthetic Titanium Ribs (VEPTRs), TGRs, MCGRs known also as MAGEC rods (Fig. 1).

VEPTRs are longitudinal rod distraction devices mainly indicated for TIS [24] or for EOS patient at risk for secondary TIS [25]. Differently from TGRs and MCGRs, VEPTRs' anchors are placed at the ribs and at the spine on the concave side to maximize the thoracic volume and the symmetry of the deformed thorax. After insertion, the patient has to undergo surgery every $4-6$ months to perform rod lengthening.

TGRs are considered the gold standard to which the other operative treatments are usually compared [26]. These distraction-based constructs provide stability and deformity correction while allowing for growth of the spine. The rod construct (or constructs, in case of dual rod) is fixated to the spine using pedicle screws or hooks. As with VEPTRs, lengthenings of the rod occur very 6-8 months, by surgery under general anaesthesia.

Every surgery performed increases wound and anaesthesia complication probability [27, 28], in addition to a higher morbidity and mortality risk. Repeated surgeries may profoundly affect children psychologically [29], in addition to delaying children's recovery time and have a huge impact on the family's finances [30]. Unlike VEPTRs and TGRs, MCGRs use an external magnetic distraction system aimed at avoiding repeated surgeries for rod lengthenings. Distractions are performed in an outpatient environment, virtually enabling more frequent rod distractions mimicking physiological spinal growth [26]. While the potential benefit of outpatient distraction procedure is huge, concerns still remain about its risks. Recently, on April 1st 2020, the
MHRA released an MDA advising not to implant MAGEC rods until further notice [7]. The MDA followed a previous FSN released by the manufacturer suspending the supply of all MAGEC rods in the UK and Republic of Ireland. Previously, on February $13^{\text {th }} 2020$, the manufacturer had published an FSN regarding the latest design of MAGEC rods (MAGEC X), reporting on the risk of a separation of the threaded end cap from the housing tube after implantation [8]. Prior to MAGEC X, six other design iterations have been commercially used (Table 2, Fig. 2).

The clinical benefits of the use of these devices remain clear, particularly in the fewer repeat operations required and less exposure to anaesthesia. Being that MAGEC rods have been extensively used in the UK and worldwide as a treatment option for severe Early-Onset Scoliosis in young patients, further considerations on the reasons for early failure of these implants must be made.

\section{Methods}

The paucity of manuscripts on risk factors affecting the safety and efficacy of MCGRs, combined to the non-uniformity of reporting complications and early failure, make meta-analysis of published literature on surgical, implant and patient (SIP) factors impossible. For this reason, a systematic qualitative literature review was carried on in this paper. The literature research was performed on Pubmed using "magec rod" or "MCGR" as keywords, in order to collect all of the available manuscripts on the topic. A total of 152 papers were found. Since MCGRs were first licensed in Europe in 2009, only papers published in the last 10 years were considered for analysis. In addition, only papers written in English were included. This first screening led to a
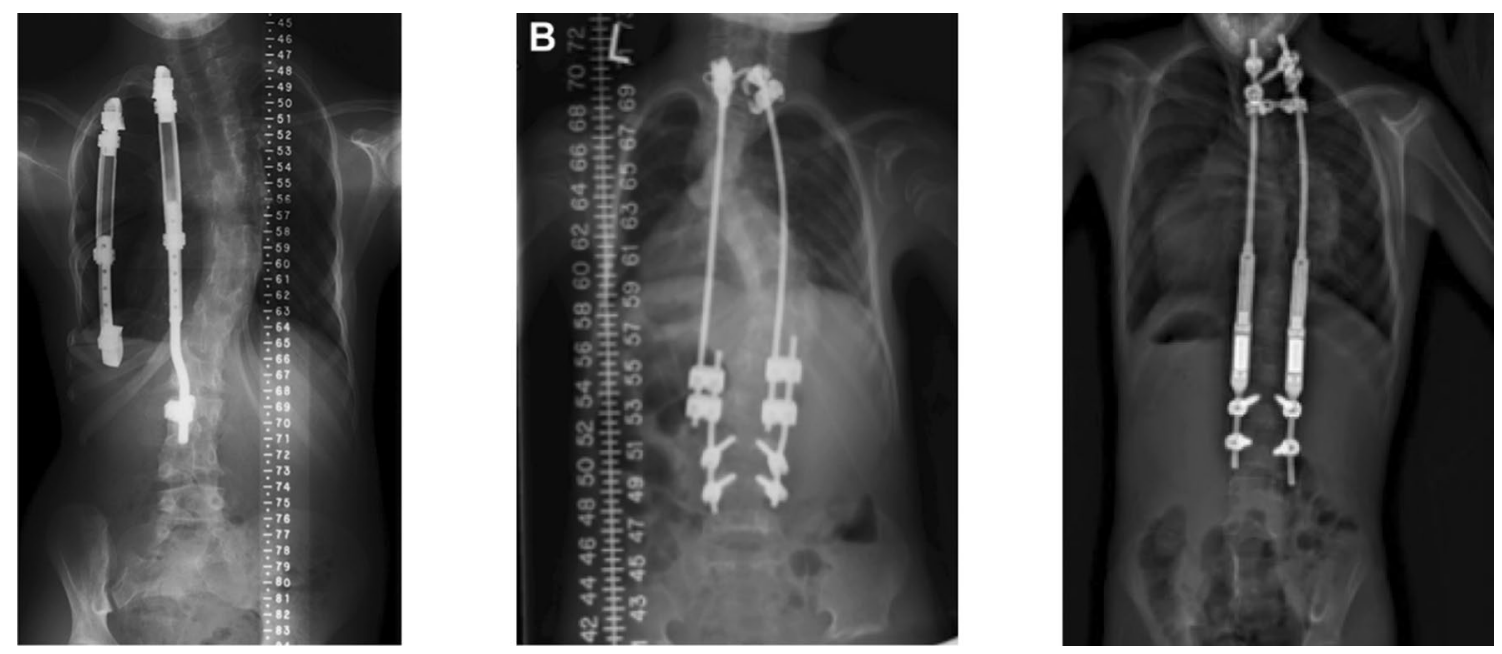

Fig. 1 From left to right: VEPTR [28], TGR [61] and MCGR [48] constructs for distraction-based techniques for the treatment of Early-Onset Scoliosis 


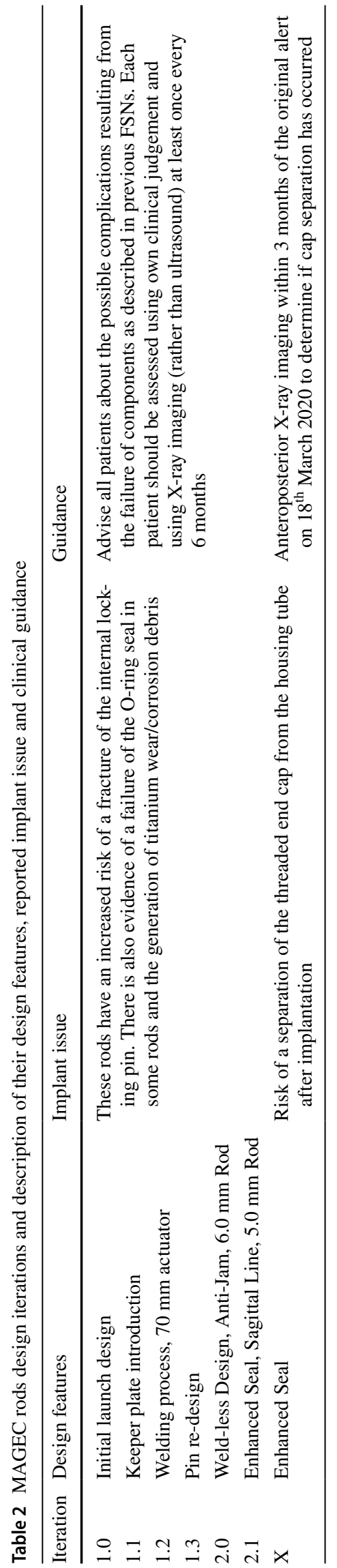

total of 129 manuscripts. The search was performed twice at 1 -month distance, giving the same results. Manuscripts performing cost-analyses or reporting questionnaire results (out of the scope of this literature review) were excluded from examination. Papers without the full text available were also excluded (Fig. 3). Finally, only papers analysing complications and failure associated with the use of MCGRs were included, leading to a total of 30 papers included (Tables 3 , $4)$.

\section{Failure of MCGRs}

Information on complication and revision rates of MAGEC rods vary among authors, due to different adopted criteria and disparate cohort sizes. A recent systematic review by Hosseini et al. [31] showed MAGEC safety and efficacy reported in literature highlighting that the majority of published studies presented results in comparison with TGRs. In order to perform an objective comparison in terms of safety and efficacy of different treatments, their outcomes should be reported in a standard way. On the contrary, the nonuniformity of reporting complications makes an objective comparison between different treatment techniques impossible [31]. However, Thakar et al. [32] in a systematic review identified the most reported complications in literature and their rates for a total of 336 patients. The most commonly reported complications were implant failure (defined as permanent loss of distraction or failure to distract), rod or rod foundation breakage and pull-out. The total unplanned revision rate in this systematic review, comprehensive of 15 studies evaluating complications, was $33.3 \%$ at 29.7 months of follow-up. More recent multicentre studies report similar results $(31.6 \%$ complication rate in a 2-year follow-up of 155 EOS patients) [33], least comparable to the revision and complication rates observed in TGR patients [34].

Teoh et al. [30] performed a direct comparison between TGRs and MCGRs complications, showing a lower complication rate of both deep and superficial infections for MCGRs, whereas metalwork problems and unplanned return to theatre were higher. The failure of the distraction mechanism represents a complication unique to the MCGR construct, whose relatively high rates were confirmed in a mean 6-year follow-up retrospective review [35]. Moreover, metallosis around failed constructs has been reported [36]. The link between the reported increased blood levels of Titanium in MCGRs and metallosis around failed implants is yet unclear [37-39]. However, high levels of Titanium in the blood serum have been considered nontoxic [40, 41] and the effects of systemic exposure to Titanium are not clear yet $[42,43]$. 


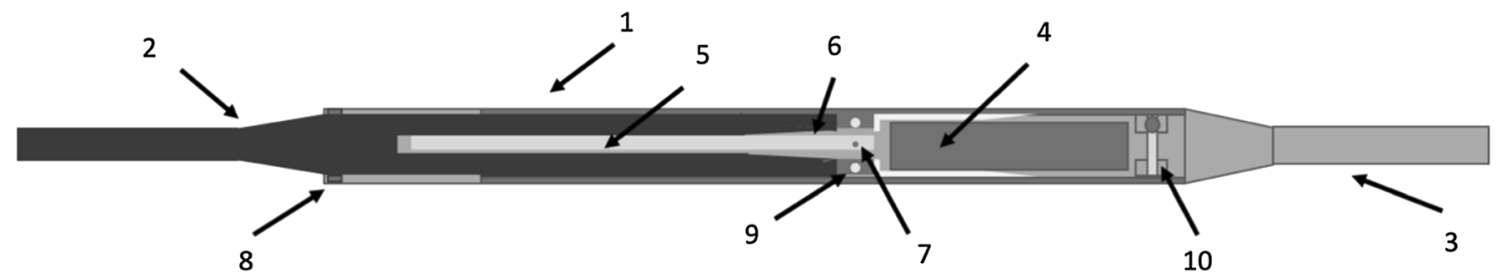

Components:

1. Housing Tube

2. End Cap

3. Distraction Rod

4. Magnet Module:

5. Lead Screw

6. Distraction Nut

7. Locking Pin

8. O-ring Seal

9. Radial Bearing

10. Thrust Bearing

Fig. 2 MAGEC 1.0 design
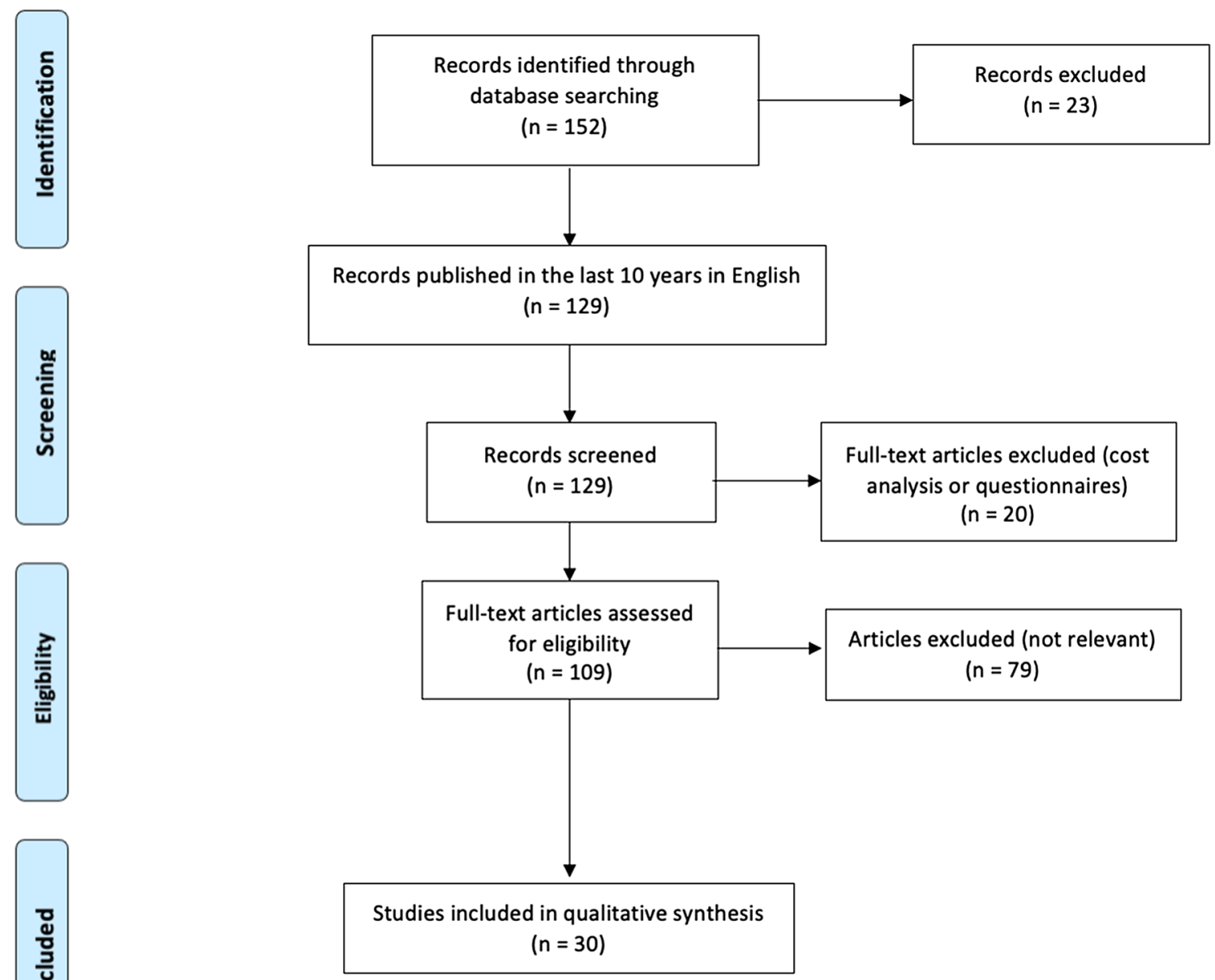

Fig. 3 Systematic review flow diagram 
Table 3 List of papers included in the systematic review and level of evidence. In case the number of patients included in the study was not available, the number of papers included in the systematic review or the number of MCGRs analysed were reported

\begin{tabular}{|c|c|c|c|c|}
\hline Author & Design & $\begin{array}{l}\text { No of patients/ No of } \\
\text { papers included }\end{array}$ & Follow-up time & $\begin{array}{l}\text { Level of } \\
\text { evidence }\end{array}$ \\
\hline Hosseini et al. [31], 2020 & Systematic review & 39 papers & & $\mathrm{V}$ \\
\hline Thakar et al. [32], 2018 & Systematic review & 336 patients/15 papers & Minimum 1 year & $\mathrm{V}$ \\
\hline Meza et al. [33], 2020 & Multicentre retrospective cohort study & 155 & Minimum 2 years & III \\
\hline Choi et al. [34], 2017 & Multicentre retrospective review of MCGR cases & 54 & 19.4 months mean & IV \\
\hline Teoh et al. [30], 2016 & Retrospective case control series & 37 & & IV \\
\hline Cheung JPY et al. [35], 2019 & Retrospective case control series & 10 & 6 years or graduate & IV \\
\hline Teoh et al. [36], 2016 & Case series & 5 & 35 months mean & VI \\
\hline Joyce et al. [37], 2018 & Retrieval study & 18 & & IV \\
\hline Rushton et al. [38], 2017 & Review & & & VII \\
\hline Yilgor et al. [39], 2018 & Multicentre, prospective, cross-sectional case series & 52 & 23 months & III \\
\hline Hosseini et al. [44], 2017 & Review & & & VII \\
\hline Dannawi et al. [45], 2013 & Prospective case series & 34 & 15 months mean & IV \\
\hline Cheung KMC et al. [3], 2012 & Prospective case series & 2 & 2 years minimum & IV \\
\hline La Rosa et al. [5], 2017 & Prospective case series & 10 & 27 months mean & IV \\
\hline Subramanian et al. [46], 2018 & Observational study & 31 & 2 years minimum & IV \\
\hline Teoh et al. [47], 2016 & Retrospective case series & 8 & 4 years & IV \\
\hline Cheung JPY et al. [26], 2019 & Review & & & VII \\
\hline Akbarnia et al. [48], 2019 & Review & & & VII \\
\hline Ridderbusch et al. [2], 2017 & Retrospective nonrandomized objective study & 35 & 1 year minimum & IV \\
\hline Lebon et al. [4], 2017 & Retrospective, consecutive, multicentre series & 30 & 18.4 months mean & IV \\
\hline Kwan et al. [49], 2017 & $\begin{array}{l}\text { Retrospective review of prospectively collected data } \\
\text { from a multicentred study }\end{array}$ & 30 & 2 years minimum & IV \\
\hline Cheung JPY et al. [50], 2018 & Prospective study & 22 & & III \\
\hline Panagiotopoulou et al. [51], 2017 & Retrieval analysis & 9 rods & & IV \\
\hline Rushton et al. [52], 2020 & Retrieval analysis & 53 & 35 months mean & IV \\
\hline Rushton et al. [53], 2019 & Retrieval analysis & 25 & 2.7 years mean & IV \\
\hline Lampe et al. [54], 2019 & Case series & 24 & 42.3 months & IV \\
\hline Poon et al. [56], 2018 & Experimental study & 12 rods & & IV \\
\hline Shaw et al. [57], 2019 & Systematic review & 20 papers & Minimum 1 year & V \\
\hline Jenks et al. [58], 2014 & Medical guidance & & Minimum 2 years & III \\
\hline Ahmad et al. [59], 2017 & Prospective study & 35 & 19.4 months mean & III \\
\hline
\end{tabular}

\section{Factors affecting Early Failure of MCGRs}

From the literature analysed in this review, some complications encountered in using MCGRs can be related to surgical, implant or patient risk factors which might be taken into consideration for implantation procedure, implant design and patient follow-up after implantation.

\section{Surgical factors}

As a first surgical factor that should be taken into consideration, MCGRs can be implanted in single or double rod configuration [44] (Fig. 4). Some surgeons might consider using single rods to prevent prominent metalware in slim patients [45], diversely increasing evidence suggests dual rods are less prone to rod breakage and slippage $[3,5,46$,
47]. For this reason, recent reports suggest the use of dual rods where possible $[26,38,48]$.

Differently from TGRs, in MCGRs rod contouring is limited to the proximal and distal regions of the rod, being that it is not allowed in the distracting mechanism portion. Accordingly, the actuator region is normally placed along the straight thoracolumbar spine [26, 48]. Following rod distractions, the flat region of the MCGR construct becomes even larger. This inability of following the sagittal curve may be related to the higher prevalence in MCGR constructs of Proximal Junctional Kyphosis (PJK) [2, 4]. On the other hand, rod contouring performed too close to the actuator region might affect its internal distracting mechanism leading to failure to achieve distraction [49] (Fig. 5).

Pedicle screws and hooks can be used to anchor the MCGR to the spine, and no superior technique has yet been 
Table 4 Research questions addressed in this systematic review and papers supporting the statements discussed with levels of evidence

\begin{tabular}{|c|c|c|c|}
\hline & Research question & Paper & $\begin{array}{l}\text { Level of } \\
\text { evidence }\end{array}$ \\
\hline \multirow[t]{11}{*}{ Failure of MCGRs } & Non-uniformity in reporting & {$[31], 2020$} & $\mathrm{~V}$ \\
\hline & \multirow[t]{4}{*}{ Complication rate } & [32], 2018 & $\mathrm{~V}$ \\
\hline & & {$[33], 2020$} & III \\
\hline & & {$[34], 2017$} & IV \\
\hline & & {$[30], 2016$} & IV \\
\hline & \multirow[t]{2}{*}{ Implant complication types } & [32], 2018 & $\mathrm{~V}$ \\
\hline & & [35], 2019 & IV \\
\hline & \multirow[t]{4}{*}{ Complication types-Metallosis } & {$[36], 2016$} & VI \\
\hline & & [37], 2018 & IV \\
\hline & & {$[38], 2017$} & VII \\
\hline & & [39], 2018 & III \\
\hline \multirow[t]{18}{*}{ Surgical risk factors } & \multirow[t]{9}{*}{ Single versus double rod configuration } & [44], 2017 & VII \\
\hline & & [45], 2013 & IV \\
\hline & & {$[3], 2012$} & IV \\
\hline & & [5], 2017 & IV \\
\hline & & [46], 2018 & IV \\
\hline & & [47], 2016 & IV \\
\hline & & [26], 2019 & VII \\
\hline & & [38], 2017 & VII \\
\hline & & {$[48], 2019$} & VII \\
\hline & \multirow[t]{5}{*}{ Rod contouring } & [26], 2019 & VII \\
\hline & & [48], 2019 & VII \\
\hline & & {$[2], 2017$} & IV \\
\hline & & [4], 2017 & IV \\
\hline & & [49], 2017 & IV \\
\hline & \multirow[t]{2}{*}{ Rod anchoring } & [26], 2019 & VII \\
\hline & & [35], 2019 & IV \\
\hline & Magnets crosstalk & {$[50], 2018$} & III \\
\hline & Rod lengthening & [49], 2017 & IV \\
\hline \multirow[t]{13}{*}{ Implant risk factors } & \multirow[t]{4}{*}{ Implant failure mechanisms } & [37], 2018 & IV \\
\hline & & {$[51], 2017$} & IV \\
\hline & & {$[52], 2020$} & IV \\
\hline & & [53], 2019 & IV \\
\hline & Pin fracture & {$[51], 2017$} & IV \\
\hline & Corrosion & {$[51], 2017$} & IV \\
\hline & \multirow[t]{2}{*}{ Wear debris } & [37], 2018 & IV \\
\hline & & [36], 2016 & IV \\
\hline & \multirow[t]{4}{*}{ Law of diminishing returns } & [4], 2017 & IV \\
\hline & & [54], 2019 & IV \\
\hline & & {$[56], 2018$} & IV \\
\hline & & {$[52], 2020$} & IV \\
\hline & Design iteration & [57], 2019 & $\mathrm{~V}$ \\
\hline \multirow[t]{3}{*}{ Patient risk factors } & Age & {$[58], 2014$} & III \\
\hline & \multirow[t]{2}{*}{ Body habitus } & {$[50], 2018$} & III \\
\hline & & [59], 2017 & III \\
\hline
\end{tabular}

identified [26], nonetheless if pedicle screws are used caution is needed when instrumenting additional levels. While this choice might help achieving better balance in particularly severe curves, foundation failure is not uncommon and re-operation requires these levels to be fused [35]. 

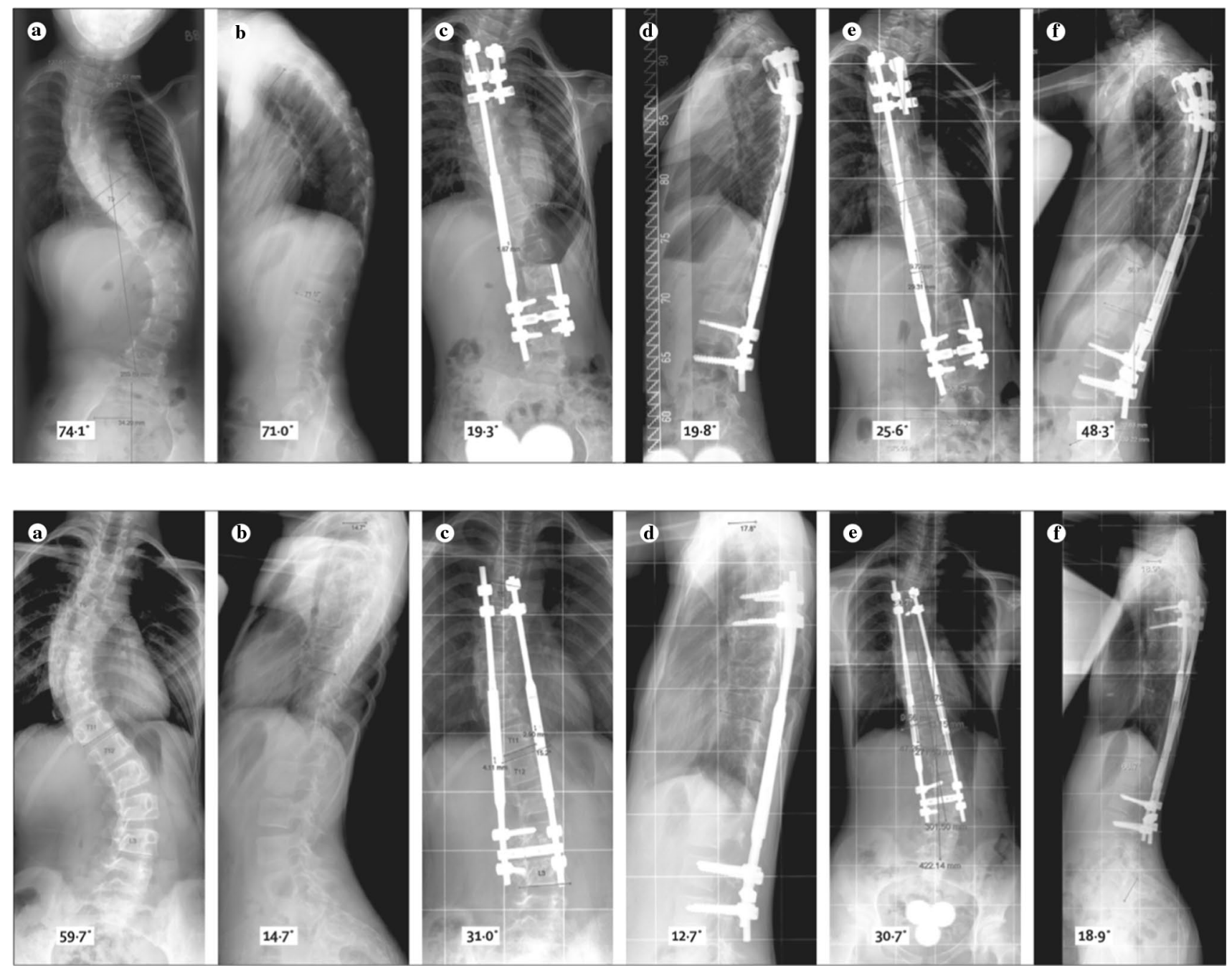

Fig. 4 Patient 1 treated with single rod construct (superior sequence) and patient 2 treated with double rod construct (inferior sequence). Posteroanterior $(\mathrm{A}, \mathrm{C}, \mathrm{E})$ and lateral $(\mathrm{B}, \mathrm{D}, \mathrm{F})$ views of preoperative spine (A, B); immediately postoperative spine $(\mathrm{C}, \mathrm{D})$, and spine at

latest follow-up (E, F) [3]. Both procedures were overall successful, even considering a minor loss of distraction at the fourth distraction procedure in patient 1 (single rod), which did not happen again in subsequent visits

Fig. 5 Example of MCGR and its structure. The explanted rod shows contouring on the proximal and distal portions of the rod

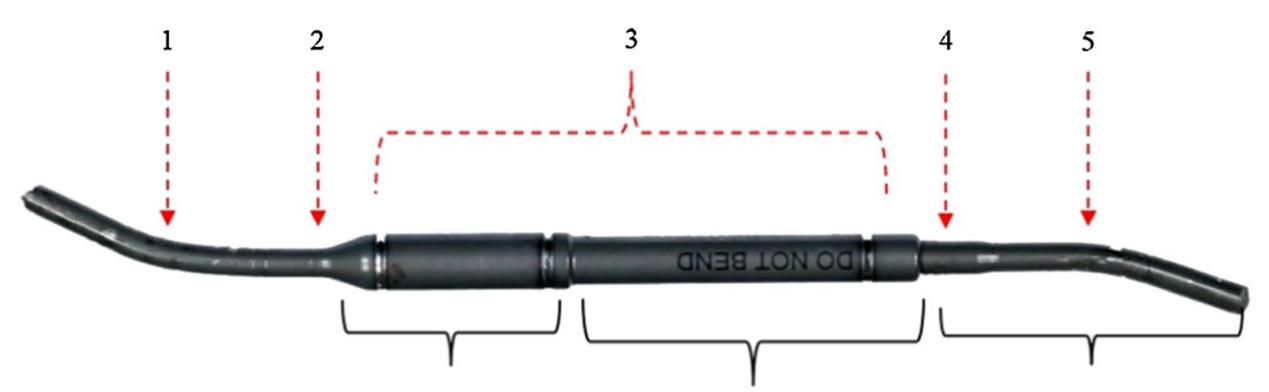

Actuator - Magnet
Actuator - Sleeve
Extendable Telescopic Rod 


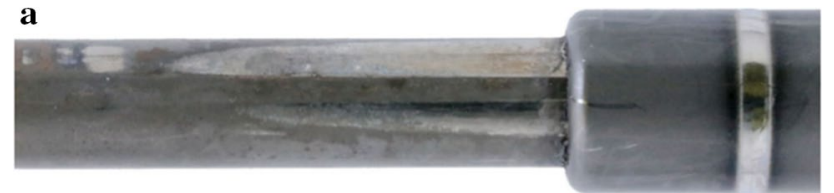

b

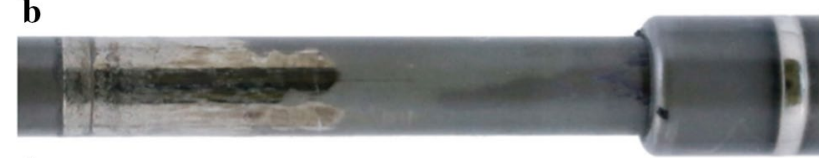

c

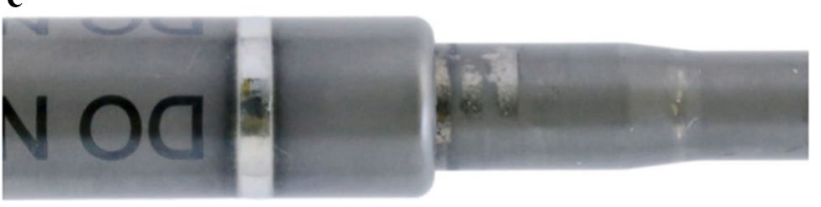

Fig. 6 Examples of different wear patterns in explanted MAGEC rods

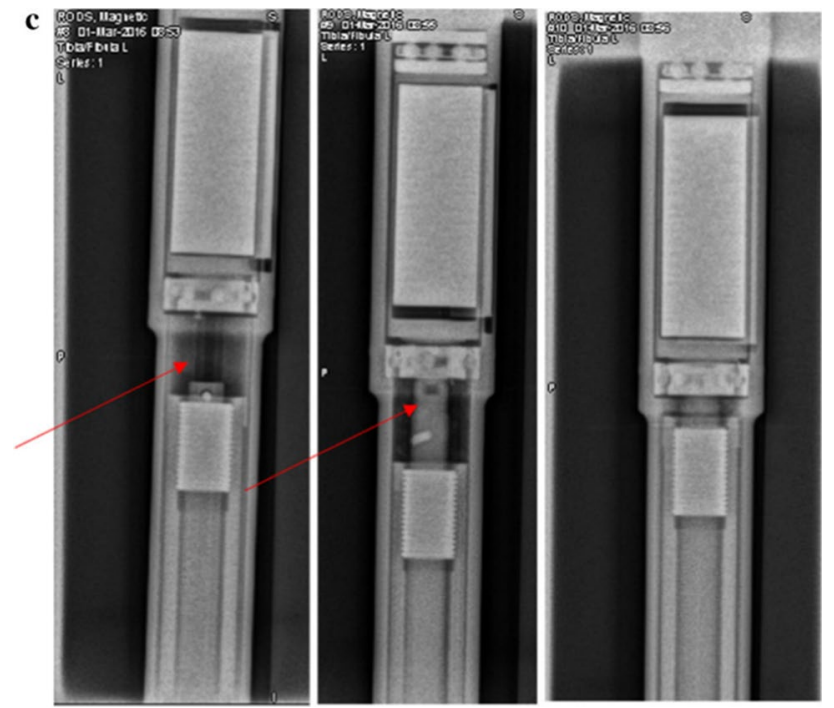

Fig. 7 Plain radiographs of three retrieved rods, two of them having a fractured mechanism as indicated by the red arrows, while the third (right) remains intact

Finally, in double rod configuration a minimum distance between rods is necessary to avoid possible rod slippage due to magnets crosstalk [50].

After rod implantation, the rod lengthening protocol is likely to influence treatment's success. Nevertheless, no consensus on the best distraction frequency or technique has yet been reached [49].

\section{Implant factors}

On the implant side, distraction mechanism failure might be due to locking pin fracture, wear of the extending bar, wear debris in the actuator region, damage to the radial bearings or O' ring seal failure [37]. Retrieval analysis of failed components helped understanding some failure mechanisms of MCGRs [37, 51-53].

The pattern of damaged surface differed from rods with intact or fractured locking pin, suggesting pin fracture as a risk factor for wear in the telescopic component of MCGRs [51] (Figs. 6, 7). A fractured pin does not necessarily equate to a loss of function in rods; normal distractions are still known to occur in some instances where a pin may have fractured. Analysing wear debris internal to the actuator region, $\mathrm{TiO}_{2}$, iron, sulphur, phosphorus, calcium and biological tissue were found. This might indicate corrosion due to fluid ingress inside the actuator, which could contribute to pin fracture [51]. Besides, failure of the seal and unbalanced loading might facilitate the exit of internally-generated wear debris, whose high volume justify the reports on metallosis around failed constructs [36, 37].

Some authors report on the applicability of the "law of diminishing returns" on MCGRs [4, 54], already showed in TGRs [55]. For MCGRs this might be linked to the diminishing distraction forces generated by the actuator as the rod lengthens $[52,56]$.

Finally, implant design iterations prior to keeper plate introduction significantly increase the probability of distraction failure [57].

\section{Patient factors}

Few patient risk factors have been proven to be linked to higher rates of complications. NICE Medical Technology Guidance recommends the use of MAGEC rods for patients aged between 2 and 11 years old, with a BMI < 25 [58]. An increased body habitus (weight, height, BMI) older age (higher DRU grade and chronological age) and increased preoperative and postoperative T1-12 and T1-S1 appeared to be linked to rod slippage [50], described as the inability of the magnet to perform a full revolution, leading to a slippage and an inability to distract the rod. No direct correlation between the aetiology of EOS and the performance of MCGRs was found in literature, probably also due to underreporting of clinical data in the evaluation of MCGRs. Some of the results found by Cheung et al. [50] are presented in Table 5. Consistently with these results, a study by Ahmad et al. [59] reported a lower T/I ratio (True/Intended distraction ratio) as the age, weight or BMI of the patient increases. It is believed that the difficulty in reaching the intended distraction is due to increased soft-tissue thickness between the External Remote Controller (ERC) and the actuator, which prevents a correct translation of forces between the two magnets, or to the generally larger bulk/mass making the distractions more challenging (Fig. 8). 
Table 5 Table summarizing the results reported by Cheung et al. regarding the patient risk factors associated with early rod slippage of MCGRs

\begin{tabular}{lcccc}
\hline $\begin{array}{l}\text { Parameter at } \\
\text { implantation }\end{array}$ & Mean \pm SD $(n=22)$ & $\begin{array}{l}\text { Mean } \pm \text { SD (early } \\
\text { slippage, } n=14)\end{array}$ & $\begin{array}{l}\text { Mean } \pm \text { SD (late or no rod } \\
\text { slippage, } n=8)\end{array}$ & $p$ value \\
\hline Height $(\mathrm{cm})$ & $137.5 \pm 16.3$ & $146.4 \pm 12.2$ & $106.4 \pm 8.5$ & 0.001 \\
Weight $(\mathrm{kg})$ & $30.0 \pm 11.2$ & $35.6 \pm 10.2$ & $17.7 \pm 2.5$ & 0.001 \\
BMI $\left(\mathrm{kg} / \mathrm{m}^{2}\right)$ & $14.9 \pm 4.7$ & $15.4 \pm 5.8$ & $12.0 \pm 1.7$ & 0.006 \\
T1-12 $(\mathrm{mm})$ & $203.7 \pm 27.9$ & $210.5 \pm 35.4$ & $185.2 \pm 14.2$ & 0.012 \\
T1-S1 $(\mathrm{mm})$ & $333.3 \pm 43.1$ & $347.0 \pm 50.8$ & $298.3 \pm 22.0$ & 0.003 \\
Age (years) & $10.2 \pm 3.4$ & $12.1 \pm 1.9$ & $7.2 \pm 2.9$ & 0.003 \\
\hline
\end{tabular}
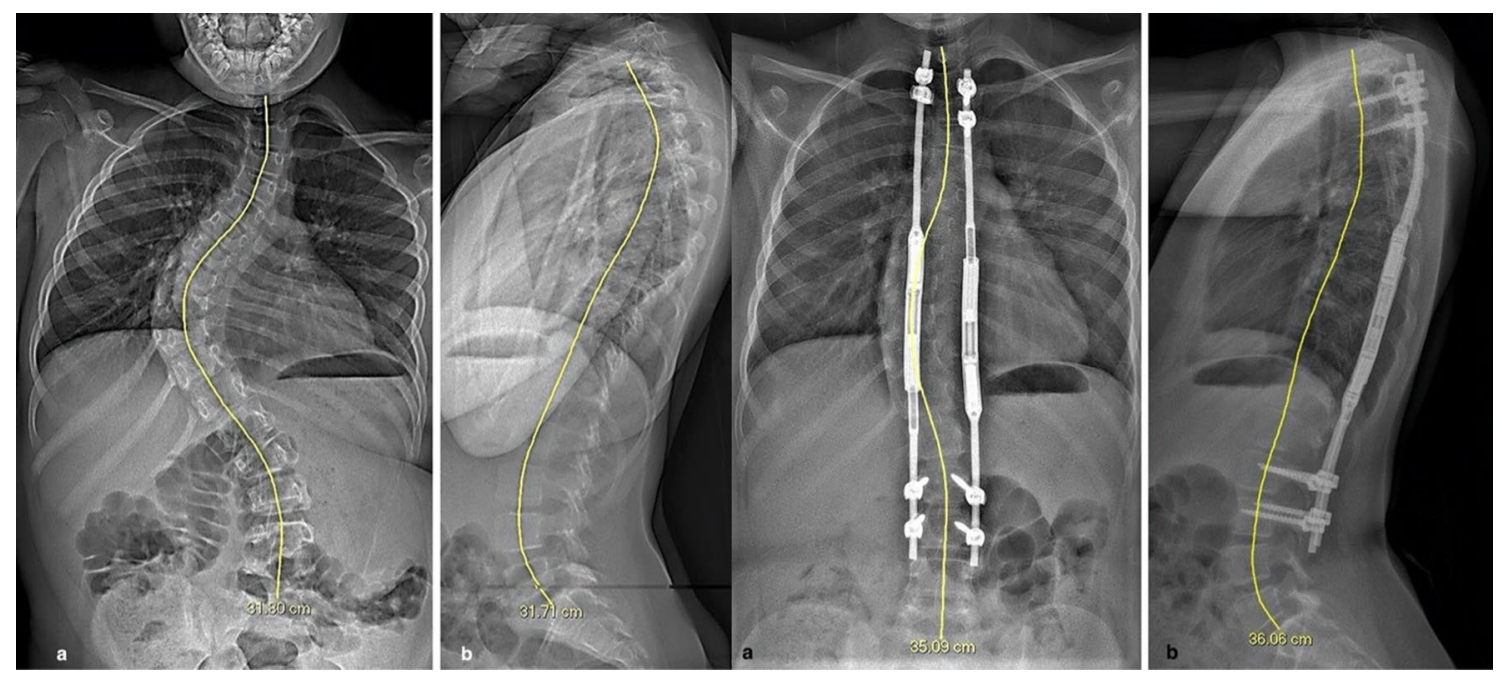

Fig. 8 Preoperative $\mathrm{x}$-ray images of a patient with a high BMI and high Cobb angle (as shown on pictures a and $\mathrm{b}$ on the left), and postoperative outcome after treatment with dual MCGR constructs (pictures a and b on the right) [62]

\section{Discussion}

Recent debate around the safety on MCGRs has led to the suspension of the supply of MAGEC rods in the UK and the Republic of Ireland. The complication profile of these devices is, on the other hand, comparable with the one associated with TGRs $[34,60]$ while lowering the number of surgeries required for the treatment. A standardized way to report on safety and efficacy of TGRs and MCGRs is required to be able to draw any comparison between different treatment modalities [26] and different studies as well. MCGRs complications reporting should take into consideration patient and treatment variables such as underlying diagnosis, number of rods implanted, type of implantation, anchorage technique, occurrence of complication by number of lengthenings and use a clear system of classification of complications [57].

From their first use, MAGEC rods have gone through several design iterations but only few authors reported on the relation between complication rate and rod iteration $[32,57]$.
While some surgical risk factors like the use of single vs dual rod construct have already been debated [26, 38, 48], analysis on the role played by rod contouring, anchoring technique and instrumented levels, rod lengthening frequency and technique need further assessment. Retrieval analysis offered a different angle from which analysing early failure of MCGR constructs, being able to identify some important implant risk factors which could be assessed by the manufacturer [37, 51-53]. A more detailed reporting of clinical data of the patients undergoing MCGRs treatment might enable a better understanding of patient risk factors associated with the use of these constructs. The relationship between failed constructs, metallosis and raised blood Titanium levels with MCGRs needs to be investigated. It is difficult to draw conclusions about the mechanisms of failure of MCGRs if all of potential surgeon, implant and patient factors are not considered; indeed all interpretation of retrieval findings must be done so with the clinical context at the forefront. A key element of this is making clear the distinction between rods that have been removed as planned (e.g. to allow for final fusion) and rods that have had to be revised (unplanned removal) due to a SIP related failure. It 
is the detailed comparison of retrieval findings, clinical and imaging data between planned and unplanned removals that will help us understand why failures occur.

\section{Conclusions}

Despite the complications reported on MCGRs, this technology still offers one of the best treatment options to spine surgeons dealing with severe EOS. The predominant surgeon, implant and patient risks factors for failure identified in this review were single rod configuration, rod positioning and contouring, locking pin fracture and patient's BMI.

Lowering the complication rate by identifying more risk factors for failure is possible through comparison of retrieval findings with comprehensive clinical and imaging data; further studies in this direction are required.

Author contributions MT, HH, EDG, MS, CN, ST, JH, AH contributed to study design/data acquisition/analysis, involved in draft of work/ revision, approved version to be published, agree to be accountable for all aspects of the work.

Funding Authors $\mathrm{HH}$ and $\mathrm{AH}$ receive institutional support from NuVasive to indipendently collect and analyse retrieved MAGEC rods. There was no funding directly for this study.

\section{Compliance with ethical standards}

Conflict of interest Authors $\mathrm{HH}$ and $\mathrm{AH}$ receive institutional support from NuVasive toindependently collect and analyse retrieved MAGEC rods. Authors MS, CN and ST use MAGEC rods in their clinical practice.

Open Access This article is licensed under a Creative Commons Attribution 4.0 International License, which permits use, sharing, adaptation, distribution and reproduction in any medium or format, as long as you give appropriate credit to the original author(s) and the source, provide a link to the Creative Commons licence, and indicate if changes were made. The images or other third party material in this article are included in the article's Creative Commons licence, unless indicated otherwise in a credit line to the material. If material is not included in the article's Creative Commons licence and your intended use is not permitted by statutory regulation or exceeds the permitted use, you will need to obtain permission directly from the copyright holder. To view a copy of this licence, visit http://creativecommons.org/licenses/by/4.0/.

\section{References}

1. Tsirikos AI, Roberts SB (2020) Magnetic controlled growth rods in the treatment of scoliosis: safety, efficacy and patient selection. Med Devices Evid Res 13:75-85. https://doi.org/10.2147/mder. s198176

2. Ridderbusch K, Rupprecht M, Kunkel P, Hagemann C, Stücker $\mathrm{R}$ (2017) preliminary results of magnetically controlled growing rods for early onset scoliosis. J Pediatr Orthop 37:e575-e580. https://doi.org/10.1097/BPO.0000000000000752

3. Cheung KMC, Cheung JPY, Samartzis D, Mak KC, Wong YW, Cheung WY, Akbarnia BA, Luk KDK (2012) Magnetically controlled growing rods for severe spinal curvature in young children: a prospective case series. Lancet 379:1967-1974. https:// doi.org/10.1016/S0140-6736(12)60112-3

4. Lebon J, Batailler C, Wargny M, Choufani E, Violas P, Fron D, Kieffer J, Accadbled F, Cunin V, De Gauzy JS (2017) Magnetically controlled growing rod in early onset scoliosis: a 30-case multicenter study. Eur Spine J 26:1567-1576. https://doi. org/10.1007/s00586-016-4929-y

5. La Rosa G, Oggiano L, Ruzzini L (2017) Magnetically controlled growing rods for the management of early-onset scoliosis: a preliminary report. J Pediatr Orthop 37:79-85. https://doi. org/10.1097/BPO.0000000000000597

6. Bin ZY, Zhang JG (2020) Treatment of early-onset scoliosis: techniques, indications, and complications. Chin Med J (Engl) 133:351-357. https://doi.org/10.1097/CM9.0000000000000614

7. MHRA (2012) Medical Device Alert MDA/2012/020. 1-4

8. NuVasive (2020) Urgent Field Safety Notice

9. Yang S, Andras LM, Redding GJ, Skaggs DL (2016) Early-onset scoliosis: a review of history, current treatment, and future directions. Pediatrics. https://doi.org/10.1542/peds.2015-0709

10. Campbell RM, Smith MD (2007) Thoracic insufficiency syndrome and exotic scoliosis. J Bone Jt Surg - Ser A 89:108-122. https:// doi.org/10.2106/00004623-200701001-00013

11. Dimeglio A, Canavese F (2012) The growing spine: How spinal deformities influence normal spine and thoracic cage growth. Eur Spine J 21:64-70. https://doi.org/10.1007/s00586-011-1983-3

12. Lenke LG (2007) The lenke classification system of operative adolescent idiopathic scoliosis. Neurosurg Clin N Am 18:199-206. https://doi.org/10.1016/j.nec.2007.02.006

13. Rosemont I United States Bone and Joint Initiative: The Burden of Musculoskeletal Diseases in the United States (BMUS), Fourth Edition

14. Williams BA, Matsumoto H, McCalla DJ, Akbarnia BA, Blakemore LC, Betz RR, Flynn JM, Johnston CE, McCarthy RE, Roye DP, Skaggs DL, Smith JT, Snyder BD, Sponseller PD, Sturm PF, Thompson GH, Yazici M, Vitale MG (2014) Development and initial validation of the classification of early-onset scoliosis (C-EOS). J Bone Jt Surg-Am 96:1359-1367. https://doi. org/10.2106/JBJS.M.00253

15. Pehrsson K, Larsson S, Oden A, Nachemson A (1992) Long-term follow-up of patients with untreated scoliosis. Spine J 17:10911096. https://doi.org/10.1097/00007632-199209000-00014

16. Fletcher ND, McClung A, Rathjen KE, Denning JR, Browne R, Johnston CE (2012) Serial casting as a delay tactic in the treatment of moderate-to-severe early-onset scoliosis. J Pediatr Orthop 32:664-671. https://doi.org/10.1097/BPO.0b013e31824bdb55

17. Johnston CE, McClung AM, Thompson GH, Poe-Kochert C, Sanders JO (2013) Comparison of growing rod instrumentation versus serial cast treatment for early-onset scoliosis. Spine Deform 1:339-342. https://doi.org/10.1016/j.jspd.2013.05.006

18. Morell SM, McCarthy RE (2016) New developments in the treatment of early-onset spinal deformity: role of the shilla growth guidance system. Med Devices Evid Res 9:241-246. https://doi. org/10.2147/MDER.S77657

19. McCarthy RE, Luhmann S, Lenke L, McCullough FL (2014) The shilla growth guidance technique for early-onset spinal deformities at 2-year follow-up: a preliminary report. J Pediatr Orthop 34:1-7. https://doi.org/10.1097/BPO.0b013e31829f92dc

20. Agarwal A, Aker L, Ahmad AA (2018) Active apex correction (modified SHILLA technique) versus distraction-based growth rod fixation: what do the correction parameters say? Spine Surg Relat Res 4(1):31-36. https://doi.org/10.22603/ssrr.2019-0045 
21. Luhmann SJ, Smith JC, McClung A, McCullough FL, McCarthy RE, Thompson GH (2017) Radiographic outcomes of shilla growth guidance system and traditional growing rods through definitive treatment. Spine Deform 5:277-282. https://doi. org/10.1016/j.jspd.2017.01.011

22. Betz RR, Ranade A, Samdani AF, Chafetz R, D'Andrea LP, Gaughan JP, Asghar J, Grewal H, Mulcahey MJ (2010) Vertebral body stapling: a fusionless treatment option for a growing child with moderate idiopathic scoliosis. Spine (Phila Pa 1976) 35:169-176. https://doi.org/10.1097/BRS.0b013e3181c6dff5

23. Skaggs DL, Akbarnia BA, Flynn JM, Myung KS, Sponseller PD, Vitale MG (2014) A classification of growth friendly spine implants. J Pediatr Orthop 34:260-274. https://doi.org/10.1097/ BPO.0000000000000073

24. Campbell R, Smith M, Hell-Vocke A (2004) Expansion thoracoplasty: the surgical technique of opening-wedge thoracostomy. J Bone Jt Surg Am 86-A(Suppl 1):51-64. https://doi. org/10.2106/00004623-200403001-00008

25. Yazici M, Emans J (2009) Fusionless instrumentation systems for congenital scoliosis: expandable spinal rods and vertical expandable prosthetic titanium rib in the management of congenital spine deformities in the growing child. Spine (Phila Pa 1976) 34:1800-1807. https://doi.org/10.1097/BRS.0b013e3181978ec9

26. Cheung JPY, Cheung KMC (2019) Current status of the magnetically controlled growing rod in treatment of early-onset scoliosis: what we know after a decade of experience. J Orthop Surg 27:1-10. https://doi.org/10.1177/2309499019886945

27. Bess S, Akbarnia BA, Thompson GH, Sponseller PD, Shah SA, El Sebaie H, Boachie-Adjei O, Karlin LI, Canale S, Poe-Kochert C, Skaggs DL (2010) Complications of growing-rod treatment for early-onset scoliosis: analysis of one hundred and forty patients. J Bone Jt Surg - Ser A 92:2533-2543. https://doi.org/10.2106/ JBJS.I.01471

28. Akbarnia BA, Emans JB (2010) Complications of growth-sparing surgery in early onset scoliosis. Spine (Phila Pa 1976) 35:21932204. https://doi.org/10.1097/BRS.0b013e3181f070b5

29. Smith JT, Campbell RM (2012) Magnetically controlled growing rods for spinal deformity. Lancet 379:1930-1931. https://doi. org/10.1016/S0140-6736(12)60528-5

30. Teoh KH, Winson DMG, James SH, Jones A, Howes J, Davies PR, Ahuja S (2016) Do magnetic growing rods have lower complication rates compared with conventional growing rods? Spine J 16:S40-S44. https://doi.org/10.1016/j.spinee.2015.12.099

31. Hosseini P, Eghbali A, Pawelek J, Heskett K, Mundis GM, Akbarnia BA (2020) A high degree of variability exists in how "safety and efficacy" is defined and reported in growing rod surgery for early onset scoliosis: a systematic review. Spine Deform 8:269283. https://doi.org/10.1007/s43390-019-00004-4

32. Thakar C, Kieser DC, Mardare M, Haleem S, Fairbank J, Nnadi C (2018) Systematic review of the complications associated with magnetically controlled growing rods for the treatment of early onset scoliosis. Eur Spine J 27:2062-2071. https://doi. org/10.1007/s00586-018-5590-4

33. Meza BC, Shah SA, Vitale MG, Sturm PF, Luhmann SJ, Anari JB (2020) Proximal anchor fixation in magnetically controlled growing rods (MCGR): preliminary 2-year results of the impact of anchor location and density. Spine Deform. https://doi. org/10.1007/s43390-020-00102-8

34. Choi E, Yaszay B, Mundis G, Hosseini P, Pawelek J, Alanay A, Berk H, Cheung K, Demirkiran G, Ferguson J, Greggi T, Helenius I, La Rosa G, Senkoylu A, Akbarnia BA (2017) Implant complications after magnetically controlled growing rods for early onset scoliosis: a multicenter retrospective review. J Pediatr Orthop 37:e588-e592. https://doi.org/10.1097/BPO.0000000000000803

35. Cheung JPY, Yiu K, Kwan K, Cheung KMC (2019) Mean 6-year follow-up of magnetically controlled growing rod patients with early onset scoliosis: a glimpse of what happens to graduates. Neurosurgery 84:1112-1123. https://doi.org/10.1093/neuros/ nyy 270

36. Teoh KH, Von Ruhland C, Evans SL, James SH, Jones A, Howes J, Davies PR, Ahuja S (2016) Metallosis following implantation of magnetically controlled growing rods in the treatment of scoliosis a case series. Bone Jt J 98-B:1662-1667. https://doi. org/10.1302/0301-620X.98B12.38061

37. Joyce TJ, Smith SL, Rushton PRP, Bowey AJ, Gibson MJ (2018) Analysis of explanted magnetically controlled growing rods from seven UK spinal centers. Spine (Phila Pa 1976) 43:E16-E22. https ://doi.org/10.1097/BRS.0000000000002221

38. Rushton PRP, Siddique I, Crawford R, Birch N, Gibson MJ, Hutton MJ (2017) Magnetically controlled growing rods in the treatment of early-onset scoliosis a note of caution. Bone Jt J 99B:708713. https://doi.org/10.1302/0301-620X.99B6.BJJ-2016-1102.R2

39. Yilgor C, Efendiyev A, Akbiyik F, Demirkiran G, Senkoylu A, Alanay A, Yazici M (2018) Metal ion release during growthfriendly instrumentation for early-onset scoliosis: a preliminary study. Spine Deform 6:48-53. https://doi.org/10.1016/j. jspd.2017.06.005

40. Jacobs JJ, Skipor AK, Patterson LM, Hallab NJ, Paprosky WG, Black J, Galante JO (1998) Metal release in patients who have had a primary total hip arthroplasty: a prospective, controlled, longitudinal study. J Bone Jt Surg - Ser A 80:1447-1458. https:// doi.org/10.2106/00004623-199810000-00006

41. de Morais LS, Serra GG, Albuquerque Palermo EF, Andrade LR, Müller CA, Meyers MA, Elias CN (2009) Systemic levels of metallic ions released from orthodontic mini-implants. Am J Orthod Dentofac Orthop 135:522-529. https://doi.org/10.1016/j. ajodo.2007.04.045

42. Cundy TP, Antoniou G, Sutherland LM, Freeman BJC, Cundy PJ (2013) Serum titanium, niobium, and aluminum levels after instrumented spinal arthrodesis in children. Spine (Phila Pa 1976) 38:564-570. https://doi.org/10.1097/BRS.0b013e3182741961

43. Krischak GD, Gebhard F, Mohr W, Krivan V, Ignatius A, Beck A, Wachter NJ, Reuter P, Arand M, Kinzl L, Claes LE (2004) Difference in metallic wear distribution released from commercially pure titanium compared with stainless steel plates. Arch Orthop Trauma Surg 124:104-113. https://doi.org/10.1007/s0040 2-003-0614-9

44. Hosseini P, Akbarnia BA (2017) Magnetically controlled growing rods: a less invasive treatment for early onset scoliosis. AME Med J 2:29-29 . https://doi.org/https://doi.org/10.21037/ amj.2017.02.09

45. Dannawi Z, Altaf F, Harshavardhana NS, El Sebaie H, Noordeen H (2013) Early results of a remotely-operated magnetic growth rod in early-onset scoliosis. J Bone Jt Surg - Ser B 95 B:75-80 . https://doi.org/https://doi.org/10.1302/0301-620X.95B1.29565

46. Subramanian T, Ahmad A, Mardare DM, Mayers D, Nnadi C, Kieser DC (2018) A six-year observational study of 31 children with early-onset scoliosis treated using magnetically controlled growing rods with a minimum follow-up of two years. Bone Jt J 100B:1187-1200. https://doi.org/10.1302/0301-620X.100B9.BJJ2018-0031.R2

47. Teoh KH, Winson DMG, James SH, Jones A, Howes J, Davies PR, Ahuja S (2016) Magnetic controlled growing rods for earlyonset scoliosis: a 4-year follow-up. Spine J 16:S34-S39. https:// doi.org/10.1016/j.spinee.2015.12.098

48. Akbarnia BA, Mundis GM (2019) Magnetically controlled growing rods in early onset scoliosis: Indications, timing and treatment. Orthopade 48:477-485. https://doi.org/10.1007/s00132-01903755-0

49. Kwan KYH, Alanay A, Yazici M, Demirkiran G, Helenius I, Nnadi C, Ferguson J, Akbarnia BA, Cheung JPY, Cheung KMC (2017) Unplanned Reoperations in Magnetically Controlled 
Growing Rod Surgery for Early Onset Scoliosis with a Minimum of Two-Year Follow-Up. Spine (Phila Pa 1976) 42:E1410-E1414. https://doi.org/10.1097/BRS.0000000000002297

50. Cheung JPY, Yiu KKL, Samartzis D, Kwan K, Tan BB, Cheung KMC (2018) Rod Lengthening with the Magnetically Controlled Growing Rod: factors influencing rod slippage and reduced gains during distractions. Spine (Phila Pa 1976) 43:E399-E405. https ://doi.org/10.1097/BRS.0000000000002358

51. Panagiotopoulou VC, Tucker SK, Whittaker RK, Hothi HS, Henckel J, Leong JJH, Ember T, Skinner JA, Hart AJ (2017) Analysing a mechanism of failure in retrieved magnetically controlled spinal rods. Eur Spine J 26:1699-1710. https://doi.org/10.1007/ s00586-016-4936-Z

52. Rushton PRP, Smith SL, Kandemir G, Forbes L, Fender D, Bowey AJ, Gibson MJ, Joyce TJ (2020) Spinal lengthening with magnetically controlled growing rods: data from the largest series of explanted devices. Spine (Phila Pa 1976) 45:170-176. https://doi. org/10.1097/BRS.0000000000003215

53. Rushton PRP, Smith SL, Forbes L, Bowey AJ, Gibson MJ, Joyce TJ (2019) Force testing of explanted magnetically controlled growing rods. Spine (Phila Pa 1976) 44:233-239. https://doi. org/10.1097/BRS.0000000000002806

54. Lampe LP, Schulze Bövingloh A, Gosheger G, Schulte TL, Lange T (2019) Magnetically Controlled Growing Rods in Treatment of Early-Onset Scoliosis: A Single Center Study with a Minimum of 2-Year-Follow up and Preliminary Results after Converting Surgery. Spine (Phila Pa 1976) 44:1201-1210. https://doi. org/10.1097/BRS.0000000000003048

55. Sankar WN, Skaggs DL, Yazici M, Johnston CE, Shah SA, Javidan P, Kadakia RV, Day TF, Akbarnia BA (2011) Lengthening of dual growing rods and the law of diminishing returns. Spine (Phila Pa 1976) 36:806-809. https://doi.org/10.1097/BRS.0b013 e318214d78f

56. Poon S, Spencer HT, Fayssoux RS, Sever R, Cho RH (2018) Maximal force generated by magnetically controlled growing rods decreases with rod lengthening. Spine Deform 6:787-790. https ://doi.org/10.1016/j.jspd.2018.03.009

57. Shaw KA, Hire JM, Kim S, Devito DP, Schmitz ML, Murphy JS (2019) Magnetically controlled growing instrumentation for early onset scoliosis: caution needed when interpreting the literature. World J Orthop 10:394-403. https://doi.org/10.5312/wjo.v10. i11.394

58. Jenks M, Craig J, Higgins J, Willits I, Barata T, Wood H, Kimpton C, Sims A (2014) The MAGEC system for spinal lengthening in children with scoliosis: a nice medical technology guidance. Appl Health Econ Health Policy 12:587-599. https://doi.org/10.1007/ s40258-014-0127-4

59. Ahmad A, Subramanian T, Wilson-Macdonald J, Rothenfluh DA, Nnadi C, Panteliadis P (2017) Quantifying the 'law of diminishing returns' in magnetically controlled growing rods. Bone Jt $\mathrm{J}$ 99B:1658-1664. https://doi.org/10.1302/0301-620X.99B12.BJJ2017-0402.R2

60. Johari AN, Nemade AS (2017) Growing spine deformities: are magnetic rods the final answer? World J Orthop 8:295-300. https ://doi.org/10.5312/wjo.v8.i4.295

61. Hosseini P, Akbarnia BA, Nguyen S, Pawelek J, Emans J, Sturm PF, Sponseller PD (2018) Construct levels to anchored levels ratio and rod diameter are associated with implant-related complications in traditional growing rods. Spine Deform 6:320-326. https ://doi.org/10.1016/j.jspd.2017.11.004

62. Abdelaal A, Munigangaiah S, Trivedi J, Davidson N (2020) Magnetically controlled growing rods in the treatment of early onset scoliosis: a single centre experience of 44 patients with mean follw-up Of 4.1 years. Bone Jt Open 1:405-414 . https://doi. org/10.14531/SS2020.1.25-41

63. Sanders JO, D’Astous J, Fitzgerald M, Khoury JG, Kishan S, Sturm PF (2009) Derotational casting for progressive infantile scoliosis. J Pediatr Orthop 29:581-587. https://doi.org/10.1097/ BPO.0b013e3181b2f8df

Publisher's Note Springer Nature remains neutral with regard to jurisdictional claims in published maps and institutional affiliations. 